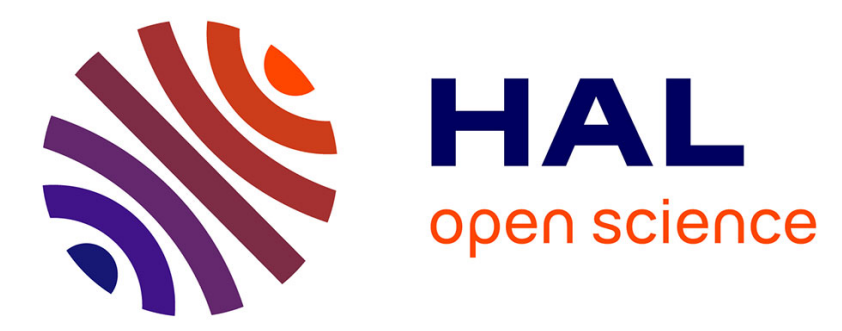

\title{
Three-Dimensional Interdigitated Microsupercapacitors with Record Areal Cell Capacitance
}

Anaïs Ferris, David Bourrier, David Pech, Daniel Guay, Sebastien Garbarino

\section{To cite this version:}

Anaïs Ferris, David Bourrier, David Pech, Daniel Guay, Sebastien Garbarino. Three-Dimensional Interdigitated Microsupercapacitors with Record Areal Cell Capacitance. Small, 2019, 15 (27), pp.1901224. 10.1002/smll.201901224 . hal-02132089

\section{HAL Id: hal-02132089 \\ https://hal.science/hal-02132089}

Submitted on 16 May 2019

HAL is a multi-disciplinary open access archive for the deposit and dissemination of scientific research documents, whether they are published or not. The documents may come from teaching and research institutions in France or abroad, or from public or private research centers.
L'archive ouverte pluridisciplinaire HAL, est destinée au dépôt et à la diffusion de documents scientifiques de niveau recherche, publiés ou non, émanant des établissements d'enseignement et de recherche français ou étrangers, des laboratoires publics ou privés. 


\section{Three-dimensional interdigitated micro-supercapacitors with record cell capacitance}

Anaïs Ferris, David Bourrier, Sébastien Garbarino, Daniel Guay*, and David Pech*

Dr. A. Ferris, D. Bourrier, Dr. D. Pech

LAAS-CNRS, Université de Toulouse, CNRS

31400 Toulouse, France

E-mail:dpech@laas.fr

Dr. A. Ferris, Dr. S. Garbarino, Prof. D. Guay

INRS-Énergie, Matériaux, Télécommunications

1650 Boulevard Lionel Boulet

Varennes, Québec, J3X 1S2, Canada

E-mail: guay@emt.inrs.ca

Dr. S. Garbarino

PRIMA Québec

505 Boulevard Maisonneuve Ouest

Montréal, Québec, H3A 3C2, Canada

Keywords: micro-supercapacitor, 3D, interdigitated, pseudocapacitance, microfabrication

Due to their high-power density and long lifetime, micro-supercapacitors have been considered as an efficient energy supply/storage solution for operation of small electronic devices. However, their fabrication remains confined to 2D thin-film microdevices with limited areal energy. In this study, the integration of all-solid-state 3D interdigitated micro-supercapacitors on 4 in. silicon wafers with record energy density is demonstrated. The device electrodes are composed of a pseudocapacitive hydrated ruthenium dioxide $\mathrm{RuO}_{2}$ deposited onto highly porous current collectors. The encapsulated devices exhibit cell capacitance of $812 \mathrm{mF} \mathrm{cm}^{-2}$ per footprint area at an energy density of $329 \mathrm{~mJ} \mathrm{~cm}^{-2}$ which is the highest value ever reported for planar configuration. These components achieve one of the highest surface energy/power densities trade-off and address the issue of electrical energy storage of modern electronics. 


\section{Introduction}

The increasing need for onboard energy supply/storage in wearable electronics, Wireless Sensor Networks and the upcoming Internet of Things has pushed for the miniaturization of a variety of technologies. In this context, the appeal to include an energy storage unit directly onto microchip is high and great efforts have been recently devoted to integrating energy harvesting ${ }^{[1-3]}$ and storage elements ${ }^{[4-6]}$ directly in microscale devices, with the objective of achieving energy self-sufficiency of embedded electronics.

Embedded Li and Li-ion micro-batteries have become the dominant energy-storage technology for electronic devices, leaving behind other rechargeable energy storage systems. ${ }^{[7,8]}$ This success relies on the unique properties of lithium (highest theoretical capacity, lowest electrochemical potential and low density) which make this element the best in term of gravimetric energy density. However, this performance metric is irrelevant to characterize onchip energy storage in microscale devices. ${ }^{[9,10]}$ Indeed, micro-batteries are to be integrated into an electronic circuitry with limited available space. The size and the compactness being the primary selection criteria, it is imperative to consider all reported properties (energy, power, etc.) normalized to the footprint area on the chip. In the light of these considerations, Li and Li-ion micro-batteries are reaching their intrinsic limitations for miniaturized microelectronic applications. Although alternative elements are now being considered, ${ }^{[11,12]}$ it remains that micro-batteries are not suitable for applications requiring safety, high power and/or long service life.

Over the last decade, micro-supercapacitors have attracted considerable attention for their use in various emerging micropower applications. A micro-supercapacitor is a miniaturized supercapacitor that can be directly mounted on a chip and work in integrated circuits. ${ }^{[13-16]}$ These small electrochemical energy storage devices are characterized by high power and excellent cyclability. However, these components have moderate energy densities because of 
their charge storage mechanisms based on interfacial reactions. ${ }^{[17]}$ The areal capacitance attainable with micro-supercapacitors based on thin-film electrodes is limited by the amount of active material involved in the charge storage. In order to improve their capacitance and energetic performances while maintaining reduced footprint, more active and accessible materials have to be loaded per unit area of electrode. This can be achieved by designing threedimensional electrodes with high surface-to-volume ratio design to have interfacial exchanges over an extended surface, thereby decoupling the direct relationship between power and energy density. The development of micro-supercapacitor electrodes with 3D architectures has received increasing interest in recent years due the impressive results using this $3 \mathrm{D}$ paradigm shift. Such electrodes rely on the deposition of pseudocapacitive materials, known for their prodigious specific capacitance, onto a high-surface-area conductive support. ${ }^{[18,19]}$ The areal capacitance is improved from one to three orders of magnitude compared to the planar geometry. ${ }^{[20-23]}$ However, the success of this approach will depend on the successful integration of these 3D electrodes on small-sized substrates and their subsequent encapsulation for operational on-chip microdevices, via commonly accepted semiconductor processing methods. In this regard, micro-supercapacitors with in-plane interdigitated electrode design ${ }^{[24-26]}$ provide flexibility and ease of integration with other small sized electronic components. This configuration also has the advantages of easy fabrication with limited number of technological steps, compatibility with all types of electrolytes (including liquid), easy adjustment of the patterns to optimize areal energy and power densities, and increased accessibility to the active electrode material as the walls of the interdigitated electrode fingers are also exposed to the electrolyte. Nevertheless, a major impediment to the realization of an interdigitated topology is the deposition of mechanically stable 3D electrode materials onto microsized patterns without shorting the positive and negative electrode. ${ }^{[27]}$

In terms of electrode materials, hydrous ruthenium dioxide stands out from other pseudocapacitive materials ${ }^{[28,29]}$ due to its high specific pseudocapacitance, excellent 
conductivity, good electrochemical reversibility and cycling stability. The minute amount of active material required in miniaturized supercapacitors makes this platinum metal group oxide affordable for microelectronic applications. The pseudocapacitive behavior of hydrous ruthenium dioxide is ascribed to a series of fast and reversible electron transfer reactions together with the electro-adsorption of protons at the electrode surface. This charge storage mechanism is not accompanied by a phase transition but with a reversible change of the oxidation states of ruthenium, which limits both chemical and structural degradation over time. Based on our previous results on a single $3 \mathrm{D}$ hydrated $\mathrm{RuO}_{2}$ electrode, ${ }^{[22]}$ the successful assembly of an interdigitated micro-supercapacitor with a record cell capacitance per footprint surface area of $812 \mathrm{mF} \mathrm{cm}^{-2}$ (i.e. $1,426 \mathrm{mF} \mathrm{cm}^{-2}$ when normalized to the active area of both electrodes), which is the highest value ever reported for a functional interdigitated microsupercapacitor, is reported. By taking advantage of the superior volumetric energy density of ruthenium dioxide, these components deliver an outstanding specific energy per footprint area of $329 \mathrm{~mJ} \mathrm{~cm}^{-2}$, making these 3D interdigitated $\mathrm{RuO}_{2}$ micro-supercapacitors competitive with Li-ion micro-batteries.

\section{Results and Discussion}

\subsection{Porous Current Collectors}

Highly porous metallic current collectors were successfully prepared using the dynamic hydrogen bubble template (DHBT) method, by which 3D self-supported metallic structures, with a wide range of interconnected pores, were electrodeposited and sculptured by $\mathrm{H}_{2}$ bubbles generated at high overpotentials. ${ }^{[30]}$ A key advantage of this technique is its cleanliness, simplicity and ease of preparation, making DHBT easily transferable to pilot production line with microelectronic facilities. 
The DHBT method was used to prepare highly porous gold architectures into which hydrated ruthenium dioxide will be subsequently deposited. The process parameters of the hydrogen bubble-assisted electrodeposition were investigated to maximize the surface area and determine the most favorable electrode morphology for electrochemical performances of $3 \mathrm{D} \mathrm{RuO}_{2}$ microsupercapacitor electrodes. As the rate of $\mathrm{H}_{2}$ evolution varies with the substrate metal, we used a strategy based on the DHBT deposition of bimetallic gold-copper AuCu alloys. Indeed, the ability of any given metal to catalyze the hydrogen evolution reaction is determined by its exchange current density and Tafel slope, ${ }^{[31,32]}$ and $\mathrm{Cu}$ is known to be a better electrocatalyst than $\mathrm{Au}$ for the hydrogen evolution reaction. Therefore, for any specific overpotential, $\mathrm{Cu}$ will generate higher volumes of $\mathrm{H}_{2}$ than $\mathrm{Au}$, leading to smaller pore sizes and thus enhanced electrochemically active surface area of the as-formed deposits. So, the porous AuCu alloys were co-electrodeposited using the DHBT technique from an equimolar mixture of $\mathrm{Au}^{3+}$ and $\mathrm{Cu}^{2+}$ salts in acidic aqueous solution at different cathodic overpotentials, which were chosen in the potential region where hydrogen evolution occurs. As we shall see, both $\mathrm{Au}$ and $\mathrm{Cu}$ are concomitantly deposited in the process.

$\mathrm{Cu}$ was then selectively removed from the bimetallic $\mathrm{AuCu}$ material using an electrochemical de-alloying approach performed in sulfuric acid electrolyte to obtain highly porous gold current collectors with extra-porosity at the nanoscale. ${ }^{[33,34]}$ The electrodissolution potential value was selected between the oxidation potentials of $\mathrm{Au}$ and $\mathrm{Cu}$ alloying elements $(0.5 \mathrm{~V}$ vs. SCE, Figure 1a), allowing the selective dissolution of the less noble $\mathrm{Cu}$ element. During the potentiostatic de-alloying step, the anodic current decreases rapidly to reach a steady-state value close to zero, indicating the depletion of accessible $\mathrm{Cu}$ in the alloy. The lattice parameters of porous $\mathrm{AuCu}$ alloys synthesized at different overpotentials lie between the values of pure $\mathrm{Au}$ (4.079 $\AA$ ) and pure $\mathrm{Cu}(3.625 \AA)$, as expected from Vegard's law. After the de-alloying process, the lattice parameters reach the one of pure Au (Figure S1, Supporting Information and Figure $1 \mathrm{~b}$ ), confirming the complete removal of $\mathrm{Cu}$ atoms from the deposits. As reported 
elsewhere, ${ }^{[35]}$ an enlargement of the crystallites size (Figure 1c) and a significant volume shrinkage take place during the electrochemical de-alloying. Also, the thickness is reduced by about $38 \%$, from $c a .74 \mu \mathrm{m}$ to $c a .46 \mu \mathrm{m}$ upon de-alloying of porous $\mathrm{AuCu}$ (Figure S2, Supporting Information). The resulting porous nature of the electrodeposited film can be observed in the SEM images of Figure 1d., where macropores are visible within an interconnected network of pore walls. At higher magnification, an ensemble of numerous $\mathrm{Au}$ dendrites is observed. They are oriented in all directions, forming mechanically stable and selfsupported pore walls. It is worth pointing out that these porous structures have a remarkable mechanical strength and exhibit a strong adherence to the substrate. To compare the surface area augmentation resulting from the internal porous nature of the current collector, an Area Enlargement Factor (AEF, Figure 1e), defined as the ratio of the electrochemically active surface area to the geometrical surface area, is calculated (see Experimental Section for details). An average AEF of 805 is obtained for de-alloyed DHBT films prepared at $-1.5 \mathrm{~V}$ vs. SCE. This value increases as the electrodeposition potential is decreased to reach a colossal AEF value of about 2,400 at $-3.5 \mathrm{vs}$. SCE (Figure 1f), which is 10 times larger than our previous result obtained with pure porous Au. ${ }^{[22]}$ Higher overpotentials lead to high-rate electrodeposition and larger thicknesses without any change of the surface morphology (Figure S3, Supporting Information). De-alloyed porous gold based on the DHBT of a co-deposited bimetallic $\mathrm{AuCu}$ films also enhances the effective surface area compared to DHBT of pure $\mathrm{Au}$ (Figure S4, Supporting Information). $\mathrm{AuCu}$ bimetallic alloys generate faster hydrogen gas evolution rates off the surface compared to pure Au deposits, reducing the available time for bubbles to coalesce. As metals grow around evolving bubbles, the average pore size of the deposited film gets smaller and the pore density increases. The subsequent de-alloying of $\mathrm{Cu}$ helps in further increasing the porosity of the deposit. 


\subsection{Three-dimensional Self-supported Electrodes}

Figure 2 shows the electrochemical properties of $3 \mathrm{D}$ electrodes after $\mathrm{RuO}_{2}$ electrodeposition (Figure S5, Supporting Information) on different de-alloyed porous metallic frameworks. Cross-sectional SEM observations show a penetration of pseudocapacitive materials inside the porous structure of the current collector from its bottom to its top (Figure S6, Supporting Information). The specific capacitance of the porous $\mathrm{Au} / \mathrm{RuO}_{2}$ electrode increases linearly with increasing number of electrodeposition cycles up to a value of $6 \mathrm{~F} \mathrm{~cm}^{-2}$ at $5 \mathrm{mV} \mathrm{s}^{-1}$ after 600 cycles (Figure 2a), which is an unprecedented performance for a micro-supercapacitor electrode. The corresponding volumetric capacitance is estimated to be $708 \mathrm{~F} \mathrm{~cm}^{-3}$, which is also superior to most of the advanced micro-supercapacitor electrode materials. ${ }^{[36]}$ The storage performance of the 3D electrode depends on the number of electrodeposition cycles (and thus thickness) of the $\mathrm{RuO}_{2}$ deposit but, surprisingly, seems unrelated to the porosity of the underlying de-alloyed porous metallic substrate. This is clearly evidenced in Figure $2 b$ where, irrespective of the AEF factor of the current collector, the specific capacitance of hydrous $\mathrm{RuO}_{2}$ normalized to the number of electrodeposited cycles is constant. The use of a 3D metal-based porous framework therefore acts exclusively as a current collector and a structural backbone for $\mathrm{RuO}_{2}$ deposition.

Figure 2c displays the experimental Nyquist plot of a 3D $\mathrm{RuO}_{2}$ electrode in de-aerated $0.5 \mathrm{M}$ $\mathrm{H}_{2} \mathrm{SO}_{4}$ electrolyte. No leakage current is observed, with a near vertical straight line in the lowfrequency region, as expected for a pseudocapacitive material. A low equivalent distributed resistance (EDR) of $c a .0 .44 \Omega \mathrm{cm}^{2}$ and an equivalent series resistance (ESR) of ca. $1.13 \Omega \mathrm{cm}^{2}$ are estimated from the high-frequency part of the spectrum (inset Figure $2 \mathrm{c}$ ). The cyclic voltammograms, recorded at different scan rates, show an almost ideal symmetrical rectangular shape (Figure 2d), revealing an easy and efficient access of both electrons and protons to the pseudocapacitive $3 \mathrm{D}$ electrode so as to afford fast and highly reversible redox 
reactions. The value of the outer capacitance $\left(\mathrm{Co}_{0}\right)$, which is related to the more accessible active surface, reaches $4.7 \mathrm{~F} \mathrm{~cm}^{-2}$ (Figure 2e) for a total capacitance $\left(\mathrm{C}_{\mathrm{t}}\right)$ of $5.0 \mathrm{~F} \mathrm{~cm}^{-2}$ (Figure 2f). This is the highest capacitance per unit area ever reported for three-dimensional microsupercapacitor electrodes, far larger than state-of-the-art thin-film micro-supercapacitor electrodes.

\subsection{Chip-scale Fabrication of 3D-interdigitated Micro-supercapacitors}

In spite of the advantages offered by the 3D architecture, the device-level integration of such 3D electrodes remains a technical challenge for the development of planar microsupercapacitors. The difficulty resides in the processing steps needed to achieve the deposition of 3D active materials with well-defined patterns and, at the same time, avoiding short circuit of the positive and negative electrodes. As the specific capacitance depends to a greater extent on the thickness of the $\mathrm{RuO}_{2}$ deposit than on the nature of the porous structure underneath, the microfabrication process of functional 3D microdevices, containing a liquid or solid electrolyte, has been experimentally validated using a standard porous gold current collector. The technological process for the integration of $3 \mathrm{D}$ electrode materials into high-resolution interdigitated patterns is depicted in Figure 3. A thin metallic sublayer (100/300 nm of Ti/Au) were first patterned onto an oxidized silicon wafer (Figure 3a) using conventional photolithography and lift-off techniques. The gap between the interdigitated fingers $(500 \mu \mathrm{m})$ as well as the electrical contact pads were then protected by a $100 \mu \mathrm{m}$-thick sacrificial layer (BPN negative photoresist, ${ }^{[37]}$ Figure $3 \mathrm{~b}$ ) to avoid subsequent electrodeposition of materials in these regions. Porous gold current collectors could then be selectively electrodeposited using the DHBT method (performed at $-1.5 \mathrm{~V} v s$. SCE for $20 \mathrm{~min}$ ) onto the conductive areas defined by the photomask (Figure 3c). The thickness and AEF of the gold current collector, which can be easily modulated by the electrodeposition parameters, were approximately $40 \mu \mathrm{m}$ and 520 , 
respectively. Pseudocapacitive hydrous ruthenium dioxide $\mathrm{RuO}_{2}$ was afterwards electrodeposited (using cyclic voltammetry at $50 \mathrm{mV} \mathrm{s}^{-1}$ from -0.3 to $+0.95 \mathrm{~V} v s$. SCE for 400 cycles) on the resulting $3 \mathrm{D}$ conducting current collector and annealed at $150^{\circ} \mathrm{C}$ for $1 \mathrm{~h} .^{[38]}$ The $\mathrm{pH}$ value of the electrolytic bath was settled at 2.5 to achieve optimal $\mathrm{RuO}_{2}$ deposition involving both chemical and electrochemical reactions. At such $\mathrm{pH}$, some ruthenium chloride precursors $\left(\mathrm{RuCl}_{3} . x \mathrm{H}_{2} \mathrm{O}\right)$ precipitate as ruthenium hydroxides, before being converted to ruthenium oxides by thermal treatment. ${ }^{\left[{ }^{[9]}\right.}$ As can be seen from SEM images in Figure 3d, $\mathrm{RuO}_{2}$ was deposited all over the wafer, including on the insulating BPN photoresist. $\mathrm{RuO}_{2}$ material on top of the photoresist was subsequently lifted-off and removed together with the sacrificial BPN layer by chemical etching, to obtain the desired pattern and leave a clean interspace between the positive and negative electrodes (Figure 3e and Figure S6, Supporting Information). The micro-supercapacitors were finally encapsulated using a low temperature packaging technique to provide a tight hermetic sealing, ${ }^{[40]}$ and tested using a liquid $\mathrm{H}_{2} \mathrm{SO}_{4}$ electrolyte as well as a solid-polymer electrolyte composed of silicotungstic acid (SiWA) in a polyvinyl alcohol (PVA) matrix. ${ }^{[41]}$ Each device was contained within a hermetic cavity obtained by bonding the silicon wafer, supporting the 3D interdigitated electrodes, to an etched silicon cap (500 $\mu \mathrm{m}$-thick, Figure S7, Supporting Information) having cavities (200 $\mu$ m-etched) which surround each device, and bonding the two wafers using a silicon glue dried for $48 \mathrm{~h}$. The resulting 3D micro-supercapacitors (footprint area $=45 \mathrm{~mm}^{2}$ ) are composed of co-planar interdigitated fingers (active surface area of each electrode $=12.8 \mathrm{~mm}^{2}$, total active surface area $=25.6 \mathrm{~mm}^{2}$ ) with rounded-terminated finger tips, as illustrated in Figure $3 \mathrm{f}$, to have a better uniform current distribution and hence better uniform active mass utilization than their rectangular counterparts. ${ }^{[42]}$ 


\subsection{Electrochemical Performances}

Looking for solid-state electrolytes having high protonic conductivity is an important precondition for developing leakage-free $\mathrm{RuO}_{2}$ micro-supercapacitors integrated on silicon wafer via microfabrication processes. We used an innovative PVA-based electrolyte doped with orthophosphoric acid $\left(\mathrm{H}_{3} \mathrm{PO}_{4}\right)$ and silicotungstic acid $\left(\mathrm{SiWA}, \mathrm{H}_{4} \mathrm{SiW}_{12} \mathrm{O}_{40}\right),{ }^{[41]}$ having an ionic conductivity of $6.1 \mathrm{mS} \mathrm{cm} \mathrm{cm}^{-1}$ after $24 \mathrm{~h}$ drying at ambient temperature. To assess the electrochemical performance of these all-solid-state devices, we compared in Figure 4a-c their cyclic voltammograms (CV) at different voltage scan rates with those based on standard liquid electrolyte $\left(0.5 \mathrm{M} \mathrm{H}_{2} \mathrm{SO}_{4}\right)$. The effect of electrolyte resistance results in a deviation from the perfectly rectangular CVs at higher scan rates (Figure 4a). This deviation is slightly more pronounced with PVA than with $\mathrm{H}_{2} \mathrm{SO}_{4}$ electrolyte. The capacitive behaviour as well as the specific capacitance increase with decreasing scan rates for both samples (Figure 4b). At $1 \mathrm{mV} \mathrm{s}^{-1}$, the capacitive effect prevails over the ohmic resistance, and the CV shape of the PVAbased micro-supercapacitor is very close to that of $\mathrm{H}_{2} \mathrm{SO}_{4}$-based micro-supercapacitors (Figure 4c). Therefore, the presence of a solid-state electrolyte does not seem to affect negatively the electrochemical behavior of the microdevice at low scan rates. Furthermore, the PVA-based microdevice can reach an extraordinary high capacitance per footprint of $812 \mathrm{mF} \mathrm{cm}^{-2}$ (Figure S8, Supporting Information) which is the highest value ever achieved for a micro-supercapacitor. This capacitance value has been normalized to the footprint area of the device to have a meaningful performance metric appropriate to real technological needs. However, it is worth pointing out that, in the future, this outstanding capacitance can be further increased by reducing the inactive gap spacing between the interdigitated fingers. Indeed, the cell capacitance reaches $1,426 \mathrm{mF} \mathrm{cm}^{-2}$ when we consider the active surface of both electrodes $\left(25.6 \mathrm{~mm}^{2}\right)$ instead of the footprint area $\left(45.0 \mathrm{~mm}^{2}\right)$. This remarkable value represents the maximum achievable footprint capacitance for the interdigitated design when the non-active 
gap is minimized. These cell capacitance values are also self-consistent with the experimentally measured electrode capacitance. The footprint area of a planar interdigitated microsupercapacitor includes the active surface areas of both electrodes and an inactive gap surface in between. The surface of each interdigitated electrode is therefore less than half of the footprint of the cell. Subsequently, the two electrodes being assembled in series, the areal capacitance of the cell $\mathrm{C}_{\text {cell }}$ is less than one-fourth of the areal capacitance of one electrode Celectrode, according to the following equation:

$$
C_{\text {cell }}=1 / 4 C_{\text {electrode }} \times \frac{25.6}{45.0}
$$

These miniaturized electrochemical capacitors can therefore deliver a specific energy of $329 \mathrm{~mJ} \mathrm{~cm}^{-2}$ per footprint area (i.e. $577 \mathrm{~mJ} \mathrm{~cm}^{-2}$ per active area), which is very close to the one of rechargeable lithium-based microbatteries. ${ }^{[10]}$

Figure 4d shows the voltage profile of the PVA-based micro-supercapacitor submitted to galvanostatic cycles from 0.25 to $1.5 \mathrm{~mA}$. All cycles exhibit a symmetrical triangular curve with a nearly linear variation of cell voltage as function of time. The IR-drop voltage $(7.2 \mathrm{mV}$ at $0.25 \mathrm{~mA}$ ) at the current switching point is also negligible, consistent with the very small ESR of the cell even with a solid-state electrolyte, and the maximum specific power per footprint area of $41.6 \mathrm{~mW} \mathrm{~cm} \mathrm{~cm}^{-2}$ (Figure S9, Supporting Information). The 3D design offers a good strategy to achieve large accessible surface area and efficient transport pathways for protons, but also fast transport for electrons from the conducting core to the redox-active material. Moreover, these 3D structures are self-supported so that no organic binder, a major contributor to the ESR, is needed. Therefore, these electronic components have not only a high energy and capacitance per unit footprint area, but also much improved power performance as well as cycle life. The long-term behaviour of the solid-state microdevice was tested by repeated galvanostatic charge/discharge cycles at high current of $1.5 \mathrm{~mA}$ (Figure 4e). The device shows stable cycling performance with almost no loss of specific capacitance after 2,000 cycles. 
Another important factor for practical use is self-discharge that causes decay of cell voltage and loss of the stored energy. Although frequently neglected in supercapacitor studies, this is a critical issue for microelectronic applications. The inset of Figure 4e shows self-discharge measurement of the solid-state 3D micro-supercapacitor performed at open-circuit conditions. The use of a solid-polymer electrolyte results in a cell that is able to operate with an extremely low self-discharge, as up to $96.0 \%$ of the initial output voltage of the device was retained after 24 hours. The solid-state electrolyte slows the diffusion of redox species thus reducing the selfdischarge effect. ${ }^{[43]}$

The overall performances of the $3 \mathrm{D} \mathrm{RuO}_{2}$ micro-supercapacitors are finally compared with state-of-the-art reports on micro-supercapacitors in an area-normalized Ragone plot (Figure 4f). In order to conduct a reliable and relevant comparison with already published data, only supercapacitor microdevices with a planar interdigitated topology have been taken into account (no stack configurations have been considered). The interdigitated configuration is more easily scalable and facilitates integration of electrochemical capacitors with Si-based electronics. The maximum areal energy density attainable by $\mathrm{RuO}_{2}$ micro-supercapacitors (in liquid and solidstate) far exceeds that of electrochemical microcapacitors based on various advanced capacitive $^{[25,36]}$ or pseudocapacitive ${ }^{[44]}$ materials, including those based on high-voltage organic or ionic liquids electrolytes. ${ }^{[27]}$ With their superior energy and power performances, these $3 \mathrm{D}$ $\mathrm{RuO}_{2}$ micro-supercapacitors fulfil the key figures of merit of energy-storage devices designed for high-power microelectronics, i.e. high specific capacitance, energy and power, cycling stability, low self-discharge and IC-compatibility.

\section{Conclusion}

We have reported successful integration of three-dimensional pseudocapacitive $\mathrm{RuO}_{2}$ electrode on a silicon wafer to realize all-solid-state interdigitated micro-supercapacitors outperforming 
the state-of-the-art. Innovative 3D active materials and integration capability in small dimension devices using suitable microfabrication techniques are the two fundamental ingredients to achieve on-chip supercapacitor microdevices with unmatched specific capacitance and noticeable performances in terms of power density, safety and long-life. More importantly, they can deliver an energy density per unit footprint area outstandingly close to that of Li-ion microbatteries, an improbable goal a couple of years ago.

The hydrogen bubble-assisted electrodeposition process has the advantage of producing 3D materials with shapes and morphologies not afforded by other synthesis approaches. The threedimensional configuration offers a means to keep transport distances short and yet provide enough material such that the supercapacitor can power electronic microsystems for extended periods of time. Furthermore, conformal and controlled coating of active materials on 3D scaffolds is expected to allow the design of electrodes with even higher power and energy characteristics. The fabrication method provides a general framework for building electrical energy-storage components with a material/process adequacy to extreme 3D architectures. This effective way opens new exciting opportunities in the field of energy storage in microscale devices and may address the issue of energy self-sufficiency in the present and emerging advanced micro-electronics.

\section{Experimental Section}

Material Synthesis: Porous AuCu alloys were prepared using the DHBT technique from an equimolar solution of $2 \mathrm{mM} \mathrm{HAuCl}_{4}$ and $2 \mathrm{mM} \mathrm{CuSO}_{4}$ in $2 \mathrm{M} \mathrm{H}_{2} \mathrm{SO}_{4}$ for $20 \mathrm{~min}$. Potentiostatic de-alloying of $\mathrm{Cu}$ was afterwards carried out in $0.5 \mathrm{M} \mathrm{H}_{2} \mathrm{SO}_{4}$ at $0.5 \mathrm{~V} v$ s. SCE. The sample was then cycled from +0.5 to $+1.6 \mathrm{~V}$ vs. SCE to completely remove $\mathrm{Cu}$. Electrodeposition of hydrous ruthenium dioxide onto the porous Au was obtained by cycling the electrode between -0.3 and $+0.95 \mathrm{~V}$ vs. SCE at $50 \mathrm{mV} \mathrm{s}^{-1}$ in a stirring solution containing $5 \mathrm{mM}$ of $\mathrm{RuCl}_{3} . x \mathrm{H}_{2} \mathrm{O}$ 
in $0.1 \mathrm{M} \mathrm{KCl}$ and $0.01 \mathrm{M} \mathrm{HCl}$, adjusted to $\mathrm{pH}=2.5$ with a $2 \mathrm{M} \mathrm{KOH}$ aqueous solution. The electrode was then annealed at $150{ }^{\circ} \mathrm{C}$ for $1 \mathrm{~h}$. The solid polymer electrolyte was prepared by mixing a PVA $\left(M_{\mathrm{W}}=31,000-50,000 / 87 \%-89 \%\right.$ hydrolyzed $)$ solution with phosphoric acid $\left(\mathrm{H}_{3} \mathrm{PO}_{4}\right)$ and silicotungstic acid ( $\left.\mathrm{SiWA}, \mathrm{H}_{4} \mathrm{SiW}_{12} \mathrm{O}_{40}\right)$ in a composition of $1.7 \mathrm{wt} \%$ PVA, $1.9 \mathrm{wt} \% \mathrm{H}_{3} \mathrm{PO}_{4}, 14.4 \mathrm{wt} \%$ SiWA, and $82 \mathrm{wt} \%$ de-ionized water.

Characterizations: The electrochemical characterizations were performed with an SP-240 BioLogic potentiostat. The surface morphology of the electrodes was examined by scanning electron microscopy (SEM) on a Hitachi S-4800 field emission electron microscope. The crystallographic structures were analyzed by X-ray diffraction (XRD) measurements on a Bruker D8 Advanced X-ray diffractometer with $\mathrm{Cu} \mathrm{K}_{\alpha}$ radiation (1.54184 А̊), operating at $40 \mathrm{kV}$ and $40 \mathrm{~mA}$. The surface chemical composition of ruthenium oxide was estimated via X-ray photoelectron spectroscopy (XPS) using a Thermo Scientific spectrometer operating with a monochromatic $\mathrm{Al} \mathrm{K} \alpha$ X-ray source $(1486.6 \mathrm{eV})$.

AEF Factor Calculation: To compare the increased surface area from the apparent geometrical surface area, the following metric named Area Enlargement Factor (AEF) is introduced:

$\mathrm{AEF}=$ Electrochemical Active Surface Area (EASA) / Geometrical Area

The electrochemical surface area of porous and bare gold electrodes is calculated using the charge associated with the reduction of gold oxide by integration, which is proportional to the real active surface area of the gold surface, using a value of $390 \mu \mathrm{C} \mathrm{cm}^{-2} \cdot{ }^{[45]}$

Data availability: The data that support the plots within this paper can be obtained free of charge from Zenodo via https://zenodo.org. 


\section{Acknowledgements}

This work was supported by LAAS-CNRS technology platform, a member of Renatech network. D. Pech acknowledges the support from the European Research Council (ERC, Consolidator Grant, ERC-2017-CoG, Project 771793 3D-CAP). D. Guay acknowledges the support of the Natural Science and Engineering Research Council (NSERC) of Canada and the Canada Research Chair (CRC) program.

\section{References}

[1] F. Hu, Q. Cai, F. Liao, M. Shao, S.-T. Lee, Small 2015, 11, 5611.

[2] F. R. Fan, W. Tang, Z. L. Wang, Adv. Mater. 2016, 28, 4283.

[3] H. Sun, Y. Zhang, J. Zhang, X. Sun, H. Peng, H., Nat. Rev. Mater. 2017, 2, 17023.

[4] B. L. Ellis, P. Knauth, T. Djenizian, Adv. Mater. 2014, 26, 3368.

[5] W. Liu, M. S. Song, Y. Cui, Adv. Mater. 2016, 29, 1603436.

[6] M. R. Lukatskaya, B. Dunn, Y. Gogotsi, Nat. Commun. 2016, 7, 12647.

[7] L. Liu, Q. Weng, X. Lu, X. Sun, L. Zhang, O. G. Schmidt, Small 2017, 13, 1701847.

[8] J. I. Hur, L. C. Smith, B. Dunn, Joule 2018, 2, 1187.

[9] Y. Gogotsi, P. Simon, Science 2011, 334, 917.

[10] N. A. Kyeremateng, R. Hahn, ACS Energy Lett. 2018, 3, 1172.

[11] M.-C. Lin, M. Gong, B. Lu, Y. Wu, D.-Y. Wang, M. Guan, M. Angell, C. Chen, J. Yang, B.-J. Hwang, H. Dai, Nature 2015, 520, 324.

[12] A. Ponrouch, C. Frontera, F. Bardé, M. R. Palacín, Nat. Mater. 2016, 15, 169.

[13] M. Beidaghi, Y. Gogotsi, Energy Environ. Sci. 2014, 7, 867.

[14] D. Qi, Y. Liu, Z. Liu, L. Zhang, X. Chen, Adv. Mater. 2017, 29, 1602802.

[15] N. Liu, Y. Gao, Small 2017, 13, 1701989.

[16] N. A. Kyeremateng, T. Brousse, D. Pech, Nat. Nanotech. 2017, $12,7$.

[17] M. Salanne, B. Rotenberg, K. Naoi, K. Kaneko, P.-L. Taberna, C. P. Grey, B. Dunn, P. Simon, Nat. Energy 2016, 1, 16070.

[18] S. Chabi, C. Peng, D. Hu, Y. Zhu, Adv. Mater. 2014, 26, 2440. 
[19] L. Liu, H. Zhao, Y. Lei, Small Methods, 2018, 1800341.

[20] T. M. Dinh, A. Achour, S. Vizireanu, G. Dinescu, L. Nistor, K. Armstrong, D. Guay, D. Pech, Nano Energy 2014, 10, 288.

[21] E. Eustache, C. Douard, R. Retoux, C. Lethien, T. Brousse, Adv. Energy Mater. 2015, $5,1500680$.

[22] A. Ferris, S. Garbarino, D. Guay, D. Pech, Adv. Mater. 2015, 27, 6625.

[23] C. Lethien, J. Le Bideau, T. Brousse, Energy Environ. Sci. 2019, 12, 96.

[24] D. Pech, M. Brunet, P.-L. Taberna, P. Simon, N. Fabre, F. Mesnilgrente, V. Conédéra, H. Durou, J. Power Sources 2010, 195, 1266.

[25] D. Pech, M. Brunet, H. Durou, P. Huang, V. Mochalin, Y. Gogotsi, P.-L. Taberna, P. Simon, Nat. Nanotech. 2010, 5, 651.

[26] W. Gao, N. Singh, L. Song, Z. Liu, A. L. M. Reddy, L. Ci, R. Vajtai, Q. Zhang, B. Wei, P. M. Ajayan, Nat. Nanotech. 2011, 6, 496.

[27] E. Eustache, C. Douard, A. Demortière, V. De Andrade, M. Brachet, J. Le Bideau, T. Brousse, C. Lethien, Adv. Mater. Technol. 2017, 2, 1700126.

[28] V. Augustyn, P. Simon, B. Dunn, Energy Environ. Sci. 2014, 7, 1597.

[29] T. Brousse, D. Bélanger, J. W. Long, J. Electrochem. Soc. 2015, 162, A5185.

[30] B. J. Plowman, L. A. Jones, S. K. Bhargava, Chem. Commun. 2015, 51, 4331.

[31] J. K. Nørskov, T. Bligaard, A. Logadottir, J. R. Kitchin, J. G. Chen, S. Pandelov, U. Stimming, J. Electrochem. Soc. 2005, 152, J23.

[32] C. G. Morales-Guio, L.-A. Stern, X. Hu, Chem. Soc. Rev. 2014, 43, 6555.

[33] X. Lang, A. Hirata, T. Fujita, M. Chen, Nat. Nanotech. 2011, 6, 232.

[34] J. Han, Y.-C. Lin, L. Chen, Y.-C. Tsai, Y. Ito, X. Guo, A. Hirata, T. Fujita, M. Esashi, T. Gessner, M. Chen, Adv. Sci. 2015, 2, 1500067.

[35] S. Parida, D. Kramer, C. A. Volkert, H. Rösner, J. Erlebacher, J. Weissmüller, Phys. Rev. Lett. 2006, 97, 035504. 
[36] P. Huang, C. Lethien, S. Pinaud, K. Brousse, R. Laloo, V. Turq, M. Respaud, A. Demortière, B. Daffos, P.-L. Taberna, B. Chaudret, Y. Gogotsi, P. Simon, Science 2016, 351, 691.

[37] D. Bourrier, M. Dilhan, A. Ghannam, L. Ourak, H. Granier, Microsyst. Technol. 2013, $19,419$.

[38] N. Yoshida, Y. Yamada, S.-I. Nishimura, Y. Oba, M. Ohnuma, A. Yamada, J. Phys. Chem. C 2013, 117, 12003.

[39] C.-C. Hu, Y.-H. Huang, Electrochim. Acta 2001, 46, 3431.

[40] H. Durou, D. Pech, D. Colin, P. Simon, P.-L. Taberna, M. Brunet, Microsyst. Technol. 2012, 18, 467.

[41] H. Gao, K. Lian, RSC Adv. 2014, 4, 33091.

[42] V. Zadin, D. Brandell, H. Kasemägi, A. Aabloo, J. O. Thomas, Solid State Ionics 2011, $192,279$.

[43] M. Xia, J. Nie, Z. Zhang, X. Lu, Z. L. Wang, Nano Energy 2018, 47, 43.

[44] K. Robert, C. Douard, A. Demortière, F. Blanchard, P. Roussel, T. Brousse, C. Lethien, Adv. Mater. Technol. 2018, 3, 1800036.

[45] S. Trasatti, O. Petrii, Pure \& Appl. Chem. 1991, 63, 711. 
a

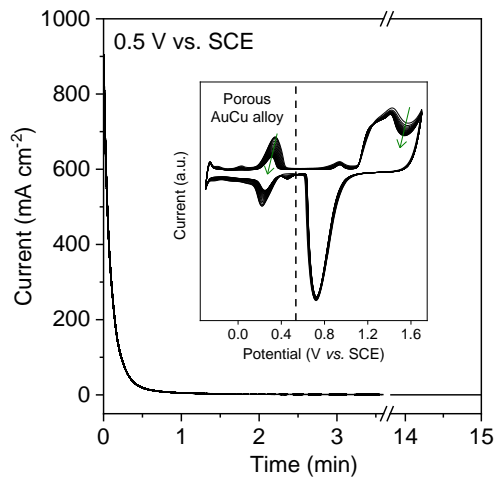

d

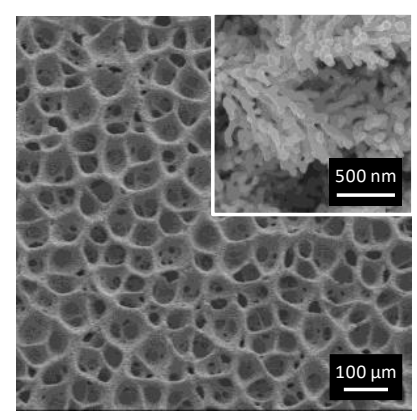

b

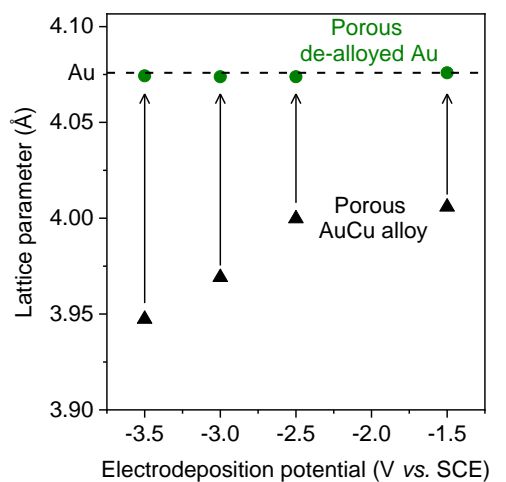

e

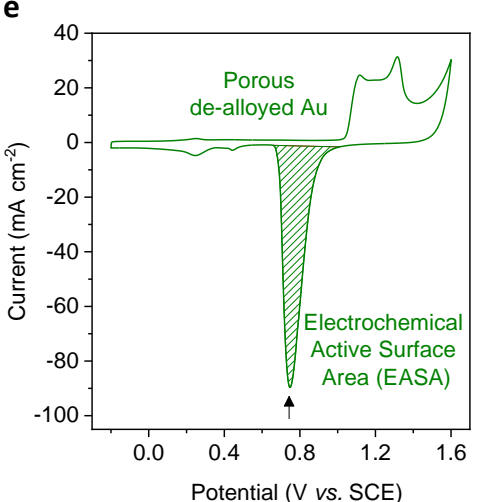

c

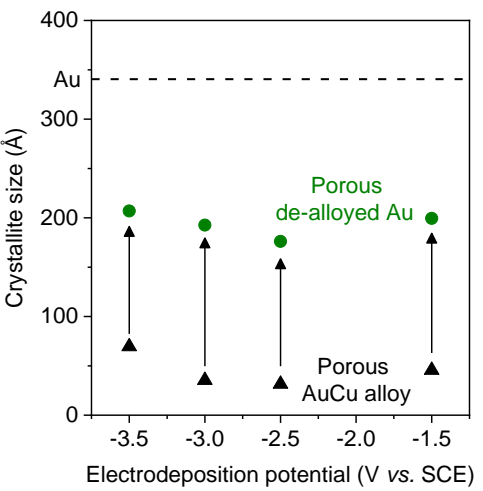

f

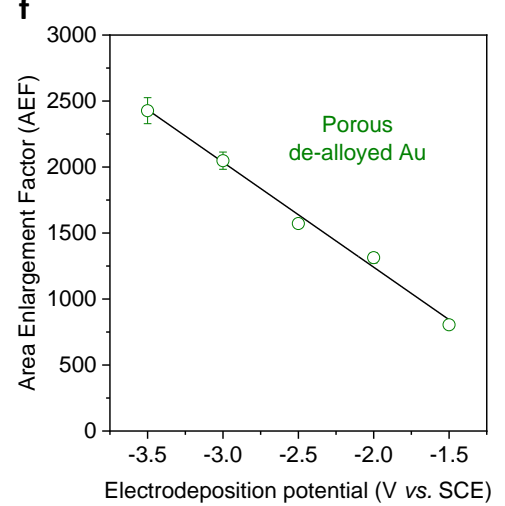

Figure 1. Porous de-alloyed gold current collectors. a) Electrochemical de-alloying of a porous $\mathrm{AuCu}$ bimetallic alloy at a constant electrode potential of $0.5 \mathrm{~V} v s$. SCE in $0.5 \mathrm{M} \mathrm{H}_{2} \mathrm{SO}_{4}$. Inset: representative cyclic voltammogram of the porous $\mathrm{AuCu}$ alloy. b) and c) Evolution of the lattice parameter (calculated using Bragg's law) and crystallite size (as measured by the Scherrer formula) of the porous $\mathrm{AuCu}$ and resulting de-alloyed porous $\mathrm{Au}-(\mathrm{Cu})$ electrodeposited at different potentials. d) and e) SEM image and cyclic voltammogram of the porous de-alloyed gold current collectors (DHBT of the bimetallic film is performed at $-1.5 \mathrm{~V} v s$. SCE before de-alloying). f) Area Enlargement Factor (AEF) determined from the Electrochemical Active Surface Area (EASA). 
a

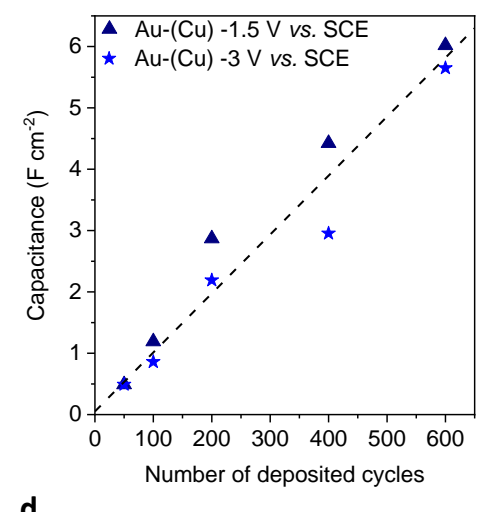

d

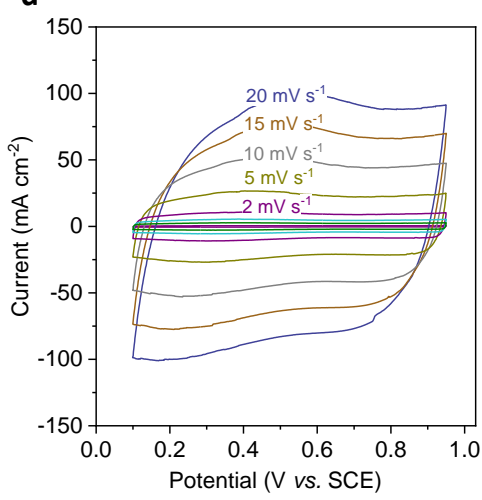

b

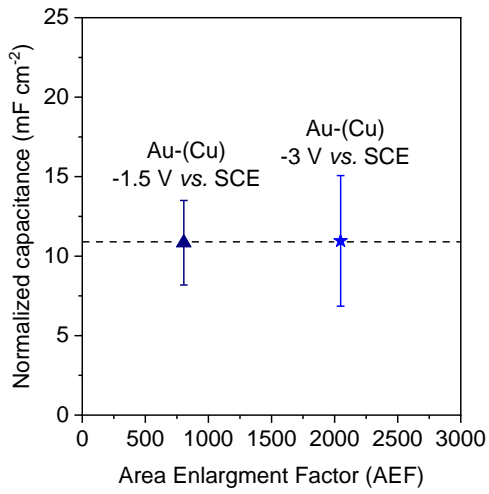

e

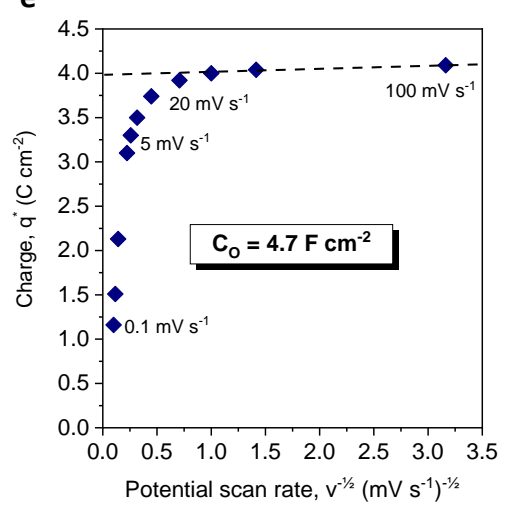

C

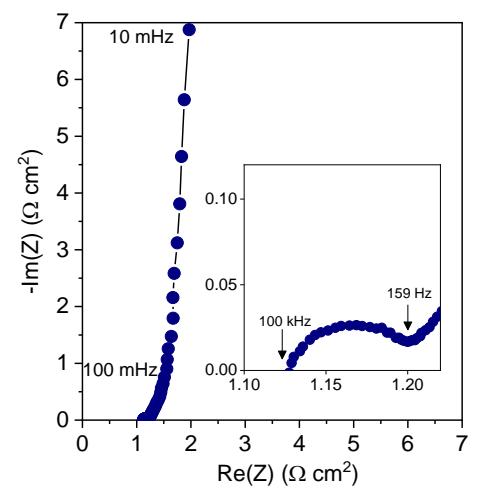

f

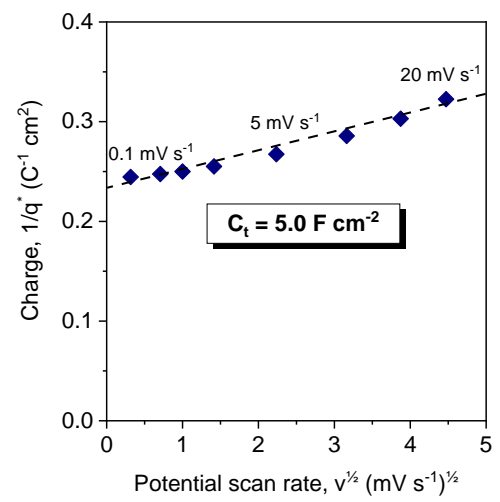

Figure 2. 3D $\mathrm{RuO}_{2}$ electrode. a) Effect of the number of $\mathrm{RuO}_{2}$ electrodeposition cycles on the capacitance of porous de-alloyed $\mathrm{Au}-(\mathrm{Cu}) / \mathrm{RuO}_{2}$ electrode at $5 \mathrm{mV} \mathrm{s}{ }^{-1}$, with $\mathrm{Au}-(\mathrm{Cu})$ samples electrodeposited at -1.5 and $-3 \mathrm{~V} v s$. SCE. b) Normalized capacitance per electrodeposition cycle of porous $\mathrm{Au}-(\mathrm{Cu}) / \mathrm{RuO}_{2}$ electrode as a function of the AEF factor. c) Representative Nyquist plot of a porous de-alloyed $\mathrm{Au}-(\mathrm{Cu}) / \mathrm{RuO}_{2}$ (400 cycles) electrode showing capacitive behaviour and low ESR (inset). d) Cyclic voltammetry profiles of the corresponding electrode collected at different scan rates. e) Determination of the outer capacitance $C_{O}$ of the electrode obtained by calculating the voltammetric charge $q^{*}$ as a function of the sweep rate $v$. f) Determination of the total capacitance $C_{t}$ of the electrode. 
a

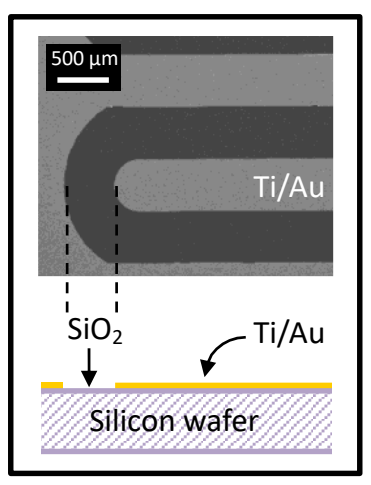

d

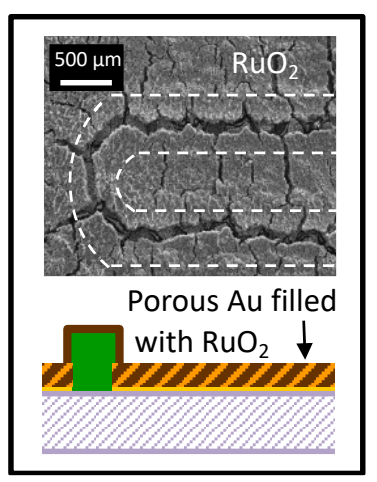

b

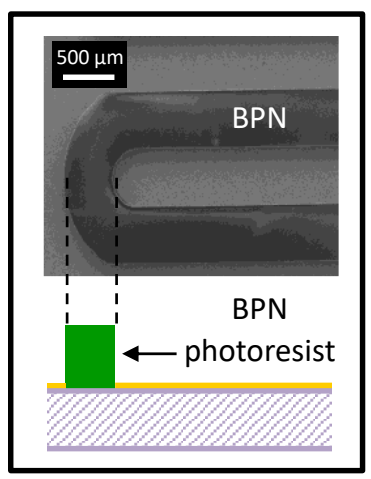

e

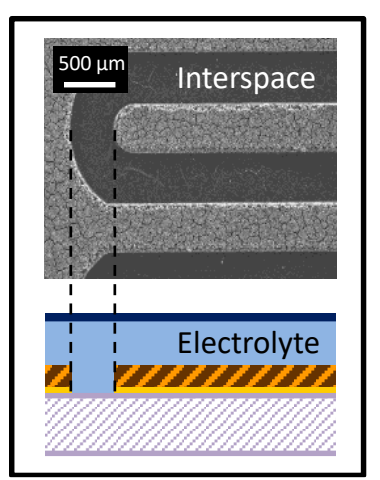

C

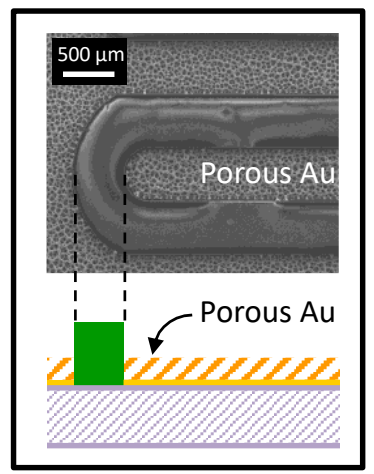

f

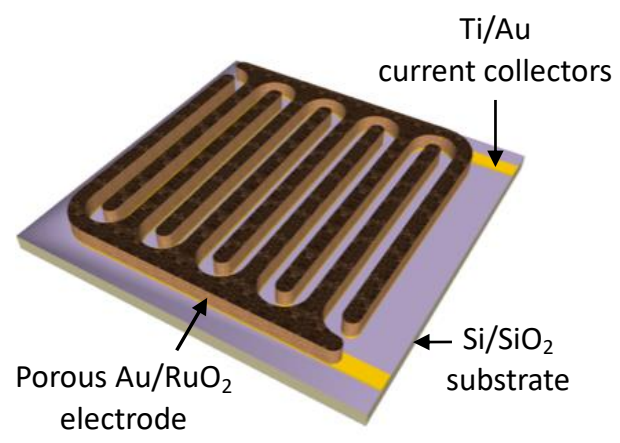

Figure 3. SEM images of the interdigitated structure at different processing steps. a) Patterned gold thin film. b) Interdigitated metallic fingers with BPN photoresist in the interspace. c) Porous gold current collector. d) Porous gold current collector with hydrated ruthenium dioxide. e) Interdigitated porous $\mathrm{Au} / \mathrm{RuO}_{2}$ electrode. f) Schematic of the final interdigitated microdevice ( $45 \mathrm{~mm}^{2}$ footprint) before electrolyte deposition and hermetic encapsulation. 

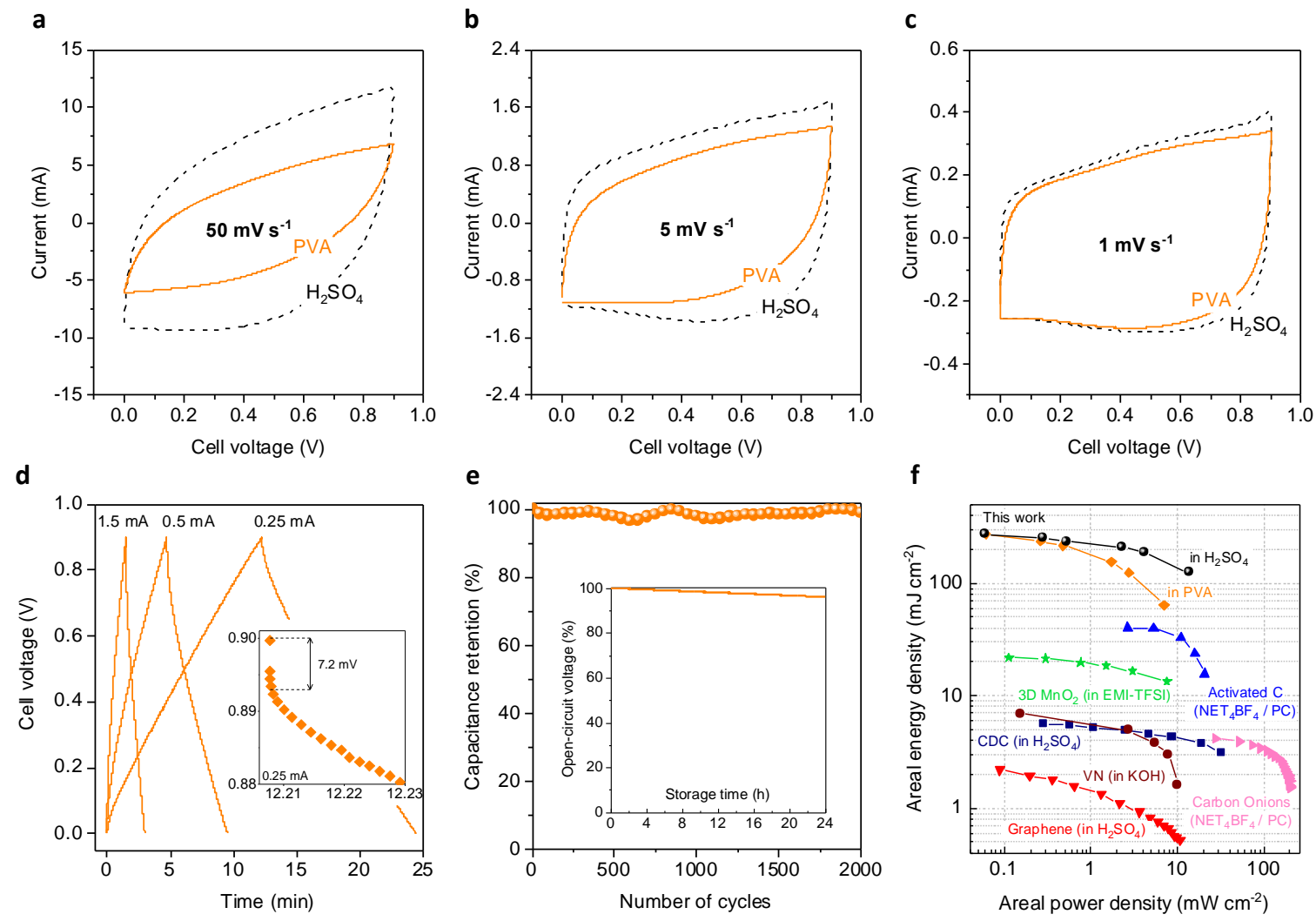

Figure 4. 3D interdigitated micro-supercapacitors. a), b) and c) Cyclic voltammograms of the interdigitated micro-supercapacitor in de-aerated $0.5 \mathrm{M} \mathrm{H}_{2} \mathrm{SO}_{4}$ and doped PVA at various scan rates. d) Galvanostatic charge/discharge curves of the PVA-based $\mathrm{RuO}_{2}$ micro-supercapacitor at different currents. e) Cell capacitance retention with the number of charge/discharge curves at $1.5 \mathrm{~mA}$. Inset: measurement of the self-discharge rate. $\mathrm{f}$ ) Ragone plot comparing the energy and power density (per footprint area) of state-of-the-art interdigitated planar microsupercapacitors. 